\title{
Contrast Involving the Performances of Different Detection Approaches to Complimentary Area Optics
}

\author{
S.R. Srividhya, S. Pothumani, D. Jeya Priya, S. Theivasigamani
}

\begin{abstract}
In this research, we have actually examined the performance of both the Modified-AND detection technique a nd the $S$ ingle Photodiode Detection strategy (SPD) in complimentary Sp ace Optics (FSO) under various rainfall climate conditions utilizing the Diagonal Eigenvalue unity (DEU) rule. The SPD method has shown better performance than the Modified-AND. At a distance of $1 \mathrm{Km}$ in FSO, the SPD supplied Error speed that is bit 10-12 while modified-AND 10-7 as a result of the reduced amount of optical to electric onversion that is $c$ additionally the wide range of photodiodes found in the $r$ eceiver aided by the S PD technique, which reduce steadily the shot noise produced. Mathematical analysis for the SPD detection method in $F$ therefore has $d$ erived. In addition, optiwave ver. 7 has been utilized to arry that is $c$ ut the simulation analysis of $b$ oth techniques.
\end{abstract}

Keywords : Multiple Access Interference (MAI), Phase Induced Intensity Noise (PIIN), Spectral Amplitude Coding (SAC), Diagonal Eigenvalue unity (DEU).

\section{INTRODUCTION}

Optical companies nowadays have to satisfy rate which is high ability need. Consequently, Optical Code Division several Access (OCDMA) as a spread range method has drawn the eye of research. O CDMA enables access that is asynchronous the system, supports random access protocols and enhances safety. But, there are numerous facets degrade OCDMA system performance such as several Access Interference (MAI) and Phase Induced Intensity sound (PIIN). As a result, a few methods have actually examined to conquer these disadvantages in OCDMA system. One of these brilliant methods is utilizing incoherent Spectral Amplitude Coding (SAC) as an scheme that is encoding. The regularity containers through the optical supply are encoded by giving or blocking them based on the rule series in incoherent SAC. Incoherent SAC has supplied performance that is better among other schemes in curbing MAI by utilizing codes have actually i deal cross correlation.

Also, its equipment realization is straightforward because of incoherent supply that is optical additionally escalates the

Revised Manuscript Received on July 22, 2019.

S.R.Sri Vidhya, Department of CSE, Bharath Institute of Higher Education and Research, Chennai, India.

S.Pothumani, Department of CSE, Bharath Institute of Higher Education and Research, Chennai, India.

D. Jeya Priya, Department of CSE, Bharath Institute of Higher Education and Research, Chennai, India.

S. Theivasigamani, Department of CSE, Bharath Institute of Higher Education and Research, Chennai, India physical bandwidth [1]. Moreover, a few detection strategies have already been utilized during the receiver part to subtract disturbance. These practices depend on a balanced receiver, which is made of two branches with two photodiodes and an subtractor that is electric. The decoder that is top gets the signature rule of users and possesses equivalent framework since the encoder, as the reduced decoder branch gets the complementary of top decoder or the binary rational AND or NAND or XOR of desired and interfering codes for Complementary [2, 3], AND [3, 4, 5], NAND $[6,7,8]$ and XOR [9, 10] subtraction strategies $r$ espectively. NAND subtraction provides better performance than complementary, plus and XOR, because it creates greater fat. In addition, Modified-AND [11]and solitary Photodiode Detection (SPD) [12] have already been utilized additionally where in actuality the sign that is optical divided in $t$ wo parts the top of o ne has got the exact same spectral once the encoder while the reduced component has the overlapping potato chips between codes. In Modified-AND the two signals subtracted from one another in electric domain whilst in SPD subtraction done in optical domain. Consequently, the SPD strategy has provided performance that is superior other subtraction methods $[13,14]$

The primary share with this scientific studies are to analyze the performance of various detection approaches to FSO making use of rule that is DEU. In area 2, a background that is theoretical FSO has introduced together with DEU rule found in comparison has presented [15, 16] The modified-AND subtraction strategy and its particular performance under various rainfall conditions has stated in area 3 . In area 4, the SPD method has talked about with mathematical analysis as well as its performance under various rainfall conditions. In area 5, an evaluation between your modified- AND plus the SPD in FSO has stated. Finally, the final outcome has stated in area 6.

\section{PROCEDURE FOR PAPER SUBMISSION}

\section{Complimentary Area Optics}

FSO has attracted the eye of research recently, and it has Discovered applications being much the telecommunication industry. As, it is very easy to setup, has resistance to interference that is electromagnetic and may be utilized in location where optical fibre cables are hard to make use of. More over, its price is significantly less than fibre cables which can be optic radio 
regularity, and unlicensed compered to microwave website link $[17,18]$. Nonetheless, FSO is affected with attenuation due to climate. Several of those attenuations are type of Sight (LOS) problem, aerosol scattering impact, Signal diminishing resulted from atmospheric turbulence, which in turn causes changes both in intensity, and stage of this light signal that is received. Weather conditions restrict the FSO performance $[19,20]$. Therefore, comprehending the sign that is optical under different weather conditions is crucial. Rain is among the environment conditions which has an attenuation influence on the signals propagate through the new air[8]. Rain attenuation is written as [21, 22]

The decoder gets the exact same reaction that is spectral the required individual. Nevertheless, the plus decoder has got the potato chips being overlapping the Where Arain could be the rainfall attenuation $\mathrm{dB} / \mathrm{Km}, \mathrm{T}$ may be the rainfall price $(\mathrm{mm} / \mathrm{hr}), \mathrm{c}$ and $\mathrm{k}$ are coefficients influenced by heat and regularity $[23,24]$. Dining table 1 shows rain that's different, their attenuation and presence

\begin{tabular}{|c|c|c|}
\hline Climate Condition & Visibility $(\mathbf{K m})$ & Attenuation $(\mathbf{d B} / \mathbf{K m})$ \\
\hline Light Fog & .5 & 18.3 \\
\hline Very Light Fog & 1.3 & 6.9 \\
\hline Light mist & 1.9 & 2 \\
\hline Clear air & 3 & 0.6 \\
\hline
\end{tabular}

Table 1: Rain Attenuation

\section{Diagonal Eigen value Unity (DEU) Code}

DEU rule construction varies according to Jordan Block matrix.This rule has construction that is simple perfect cross correlation $0 \leq \lambda \mathrm{c} \leq 1$, supports a higher wide range of users, and it has free cardinality in picking the rule fat and the quantity of users. Consequently, its one of many promising codes to be used as time goes on system [5] that is optical [25, 26].

\section{$\square 1111000000000000000000000 \square$}

$\square 0001111000000000000000000 \square$

$\square 0000001111000000000000000 \square$

0000000001111

\section{$\square \square$ \\ $\square 000000000000 \square$ \\ $\square 0000000000001111000000000 \square$ \\ $\square \square$ \\ $\square 0000000000000001111000000 \square$ \\ $\square 0000000000000000001111000 \square$ \\ $\square \square$ \\ $\square \square 0000000000000000000001111 \square \square$}

Assume that we now have two rule that is significantly diffent
Hi $\square \square \mathrm{H} 1, \mathrm{H} 2, \ldots \ldots . . \mathrm{HL} \square$ and Fi $\square \square \mathrm{F} 1, \mathrm{~F} 2, \ldots \ldots \ldots . . . \mathrm{FL}$

$\square$ The

cross-correlation between your two rule sequences is written as [27, 28, 29] rule series along with other codes. The 2 signals are detected by the 2 photodiodes and sign through the then reduced branch subtracted through the top someone to expel disturbance sign. Finally, the production sign is pass that is low [30, 31].

Figure 2 and 3 show the variation of BER versus the exact distance as well as the beam divergence under light mist and extremely light $\mathrm{f}$ og condition in which the attenuation equal 2 and $6.9 \mathrm{~dB} / \mathrm{km}$ correspondingly. Numbers suggest that the performance associated with the modified-AND detection strategy under light mist condition surpasses extremely fog that is light the attenuation is less. As the amplitude is paid down by the attenuation regarding the sign received. In addition, figure 4 shows the variation associated with charged energy gotten utilizing the distance. What this means is that because the distance escalates the charged energy $r$ eceived decreases. Tabel 2 states the parameters uesd in the simulation.

\begin{tabular}{|c|c|c|c|}
\hline $\begin{array}{c}\text { Each } \\
\text { chip }\end{array}$ & $.8 \mathrm{~nm}$ & $\begin{array}{c}\text { Bea } \\
\mathbf{m}\end{array}$ & $2 \mathrm{mrad}$ \\
\hline Data rate & $\begin{array}{c}622 \\
\mathrm{Mbps}\end{array}$ & Dark current & $5 \mathrm{nA}$ \\
\hline $\begin{array}{c}\text { Distance } \\
\text { (FSO) }\end{array}$ & $\begin{array}{c}100-100 \\
0\end{array}$ & $\begin{array}{c}\text { Thermal } \\
\text { noise }\end{array}$ & $\begin{array}{c}1.8 \times 10^{-23} \\
\mathrm{w} / \mathrm{H}\end{array}$ \\
\hline $\begin{array}{c}\text { Trans } \\
\text { mitte }\end{array}$ & $10 \mathrm{~cm}$ & $\begin{array}{c}\text { Low pass } \\
\text { filter }\end{array}$ & $.75 \mathrm{GHZ}$ \\
\hline $\begin{array}{c}\text { receiver } \\
\text { aperture }\end{array}$ & $32 \mathrm{~cm}$ & wavelength & 1550 \\
\hline
\end{tabular}

Table 2: the parameters uesd in the simulation

\section{SOLITARY PHOTODIODE DETECTION (SPD) TECHNIQUE}

Figure 5 shows the SAC-OCDMA receiver side SPD that is making use of method. The received optical sign is decoded by the decoder which has similar spectral $r$ esponse since the sign that is encoded. The decoder production is add up to w for desired user or 1 for interferences [32, 33]. Where $\mathrm{w}$ represents the amount of one's into the individual rule, and 1 may be the cross that is in-phase, which represents the utmost number of overlapping potato chips between any two codes sequences. Then, the others is gotten by the subtraction decoder associated with sign through the decoder to remove[34, 35].

\section{MODIFIED-AND DETECTION TECHNIQUE}

Figure 1 shows the SAC - OCDMA receiver on the basis of the Modified-AND strategy. The sign that is optical is divided in to two components. Someone to the decoder that is top one other to your AND decoder through an attenuator. The attenuator guarantees that the disturbance sign has got the exact same energy event for each picture detector when it comes to an user that is inactive.for disturbance. Finally, the optical subtractor production is detected by a 
PIN photodiode and low pass filtered to reject regularity sound that is high [36]. This system has advantage that is many as eliminating both MAI and PIIN within the optical domain, reduce steadily the shot sound as one photodiode is employed, enhances throughput and price effective. When compared with other subtraction methods that cancel disturbance in $t$ he electric domain, which increase range optical to transformation that is electric. In addition they utilize two photodiodes, which boost the shot sound [37].

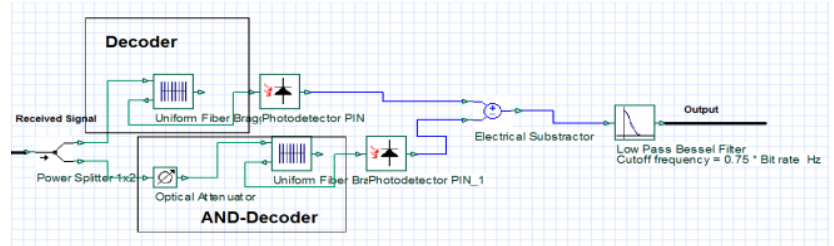

Figure 1: SAC - OCDMA receiver considering Modified-AND method

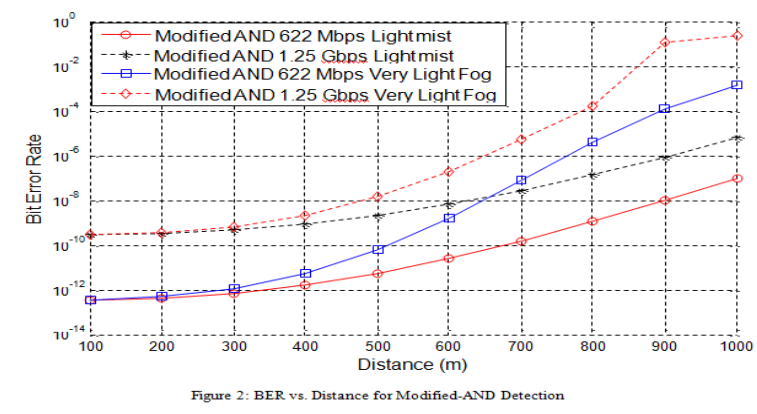

Figure 2: BER vs. Distance for Modified-AND Detection Modified AND 622 Mbps Light mist Modified AND 1.25 Gbps Light mist Modified AND 622 Mbps really Light Fog Modified AND 1.25 Gbps really fog that is light

The mean energy that is optical the p hoto-diode is written as [38] become equal for $\mathrm{s}$ analysis that is implifying Bo may be the optical bandwidth split into rational regularity containers of width $\mathrm{Bo} / \mathrm{L}, \mathrm{He}(\mathrm{v})$ and $\mathrm{Hd}(\mathrm{v})$ will be the encoder and decoder transfer functions, correspondingly. $\mathrm{Ce}(\mathrm{i})$ and $\mathrm{Cd}(\mathrm{i})$ suggest the element that is ith

of the encoder and decoder rule terms, correspondinglyThe shot noise $v$ ariance may be expressed as [39]

whereerfc could be the mistake function complementary.Figure 6 and 7 show the variation of BER versus the distance plus the beam divergence under light mist and extremely fog that is light correspondingly. Numbers suggest that the performance of SPD detection method under light mist condition surpasses really fog that is light the attenuation is less. Also, as much as $500 \mathrm{~m}$ the performance is the identical underneath the two conditions. The noise that's thermal could be written as [40] $\square$ $2 \square$ BTn that is $4 \mathrm{~K}$ (8) the exact distance boost the weather effect became significant.

Furthermore, the variation of beam divergence has less effect on SPD detection strategy performance than modified-AND. In addition, figure 8 shows the variation for the charged energy gotten because of the distance. It demonstrates that while the distance advances the RL The PIIN for unpolarized light that is thermal can be expressed as [41] Bo energy received decreases.

\section{EFFECTS AND CONVERSATION}

FSO Numbers 9 and 10 show the variation of BER versus the exact distance and the beam divergence for the SPD and the modified-AND detection strategy. Too, figure 11 programs the variation of energy gotten with distance for both practices. Numbers claimed that the SPD method has supplied better performance compared to the modified-AND $\mathrm{d}$ ue to reduction o f electrical to transformation that is optical and making use of solitary photodiode rather than two within the modified-AND, which reduce steadily the shot sound during the receiver part.

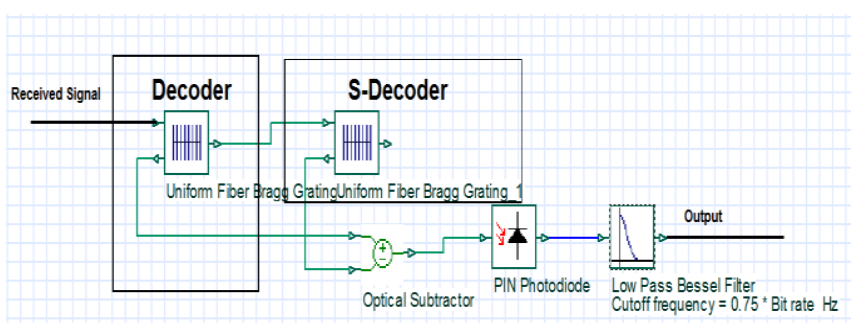

Figure 3: SAC-OCDMA receiver according to SPD method

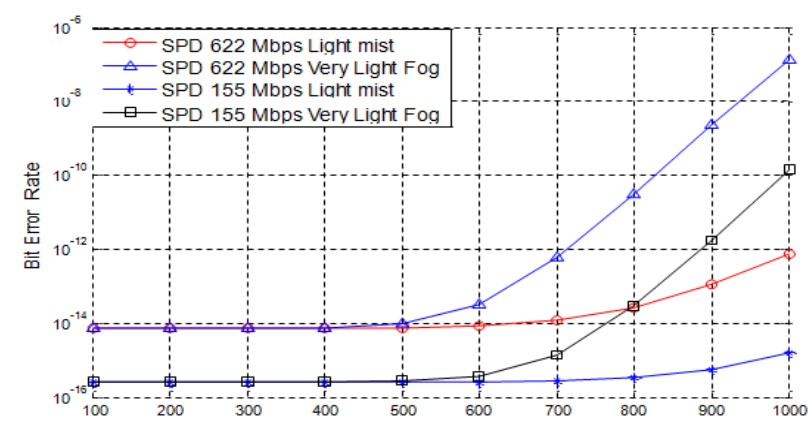

Figure 4: BER vs. Distance for SPD

\section{CONCULSION}

We've examined the performance of DEU rule as a rule that is guaranteeing future optical system in FSO. Additionally, an evaluation involving the performance o $\mathrm{f}$ both the modified-AND together with SPD detection techniques DEU that is utilizing in has stated. We utilized SAC that is incoherent in this research, because it has better transmission performance than many other schemes. The SPD strategy supplied better performance compared to modified-AND, whilst the subtraction procedure done within the domain that is optical which decrease the optical to electric transformation procedures together with range photo-detectors utilized during the receiver part.

\section{REFERENCES}

[1] Kumaravel A., Rangarajan K.,Algorithm for automaton specification for exploring dynamic labyrinths,Indian Journal of Science and Technology,V-6,I-SUPPL5,PP-4554-4559,Y-2013

[2]P. Kavitha, S. Prabakaran "A Novel Hybrid Segmentation Method with Particle Swarm Optimization and Fuzzy C-Mean Based On Partitioning the Image for Detecting Lung Cancer" International Journal of Engineering and Advanced Technology (IJEAT) ISSN: 2249-8958, Volume-8 Issue-5, June 2019

[3] Kumaravel A., Meetei O.N.,An application of non-uniform cellular automata for efficient cryptography,2013 IEEE 
Conference on Information and Communication Technologies, ICT 2013,V-,I-,PP-1200-1205,Y-2013

[4] Kumarave A., Rangarajan K.,Routing alogrithm over semi-regular tessellations,2013 IEEE Conference on Information and Communication Technologies, ICT 2013,V-,I-,PP-1180-1184,Y-2013

[5]P. Kavitha, S. Prabakaran "Designing a Feature Vector for Statistical Texture Analysis of Brain Tumor" International Journal of Engineering and Advanced Technology (IJEAT) ISSN: 2249-8958, Volume-8 Issue-5, June 2019

[6] Dutta P., Kumaravel A.,A novel approach to trust based identification of leaders in social networks,Indian Journal of Science and Technology,V-9,I-10,PP--,Y-2016

[7] Kumaravel A., Dutta P.,Application of Pca for context selection for collaborative filtering,Middle - East Journal of Scientific Research,V-20,I-1,PP-88-93,Y-2014

[8] Kumaravel A., Rangarajan K.,Constructing an automaton for exploring dynamic labyrinths,2012 International Conference on Radar, Communication and Computing, ICRCC 2012,V-,I-,PP-161-165,Y-2012

[9]P. Kavitha, S. Prabakaran "Adaptive Bilateral Filter for Multi-Resolution in Brain Tumor Recognition" International Journal of Innovative Technology and Exploring Engineering (IJITEE) ISSN: 2278-3075, Volume-8 Issue-8 June, 2019

[10] Kumaravel A.,Comparison of two multi-classification approaches for detecting network attacks, World Applied Sciences Journal,V-27,I-11,PP-1461-1465,Y-2013

[11] Tariq J., Kumaravel A.,Construction of cellular automata over hexagonal and triangular tessellations for path planning of multi-robots,2016 IEEE International Conference on Computational Intelligence and Computing Research, ICCIC 2016,V-,I-,PP--,Y-2017

[12] Sudha M., Kumaravel A.,Analysis and measurement of wave guides using poisson method,Indonesian Journal of Electrical Engineering and Computer Science, V-8,I-2,PP-546-548,Y-2017

[13] Ayyappan G., Nalini C., Kumaravel A.,Various approaches of knowledge transfer in academic social network,International Journal of Engineering and Technology,V-,I-,PP-2791-2794,Y-2017

[14] Kaliyamurthie, K.P., Sivaraman, K., Ramesh, S. Imposing patient data privacy in wireless medical sensor networks through homomorphic cryptosystems 2016, Journal of Chemical and Pharmaceutical Sciences92.

[15] Kaliyamurthie, K.P., Balasubramanian, P.C. An approach to multi secure to historical malformed documents using integer ripple transfiguration 2016 Journal of Chemical and Pharmaceutical Sciences92.

[16] A.Sangeetha,C.Nalini,"Semantic Ranking based on keywords extractions in the web", International Journal of Engineering \& Technology, 7 (2.6) (2018) 290-292

[17] S.V.GayathiriDevi,C.Nalini,N.Kumar,"An efficient software verification using multi-layered software verification tool "International Journal of Engineering \& Technology, 7(2.21)2018 454-457

[18] C.Nalini,ShwtambariKharabe,"A Comparative Study On Different Techniques Used For Finger - Vein Authentication", International Journal Of Pure And Applied Mathematics, Volume 116 No. 82017 , 327-333, Issn: 1314-3395

[19] M.S. Vivekanandan and Dr. C. Rajabhushanam, "Enabling Privacy Protection and Content Assurance in Geo-Social Networks", International Journal of Innovative Research in Management, Engineering and Technology, Vol 3, Issue 4, pp. 49-55, April 2018.

[20] Dr. C. Rajabhushanam, V. Karthik, and G. Vivek, "Elasticity in Cloud Computing", International Journal of Innovative Research in Management, Engineering and Technology, Vol 3, Issue 4, pp. 104-111, April 2018.

[21] K. Rangaswamy and Dr. C. Rajabhushanamc, "CCN-Based Congestion Control Mechanism In Dynamic Networks", International Journal of Innovative Research in Management, Engineering and Technology, Vol 3, Issue 4, pp. 117-119, April 2018.

[22] Kavitha, R., Nedunchelian, R., "Domain-specific Search engine optimization using healthcare ontology and a neural network backpropagation approach", 2017, Research Journal of Biotechnology, Special Issue 2:157-166

[23] Kavitha, G., Kavitha, R., "An analysis to improve throughput of high-power hubs in mobile ad hoc network" ,2016, Journal of Chemical and Pharmaceutical Sciences, Vol-9, Issue-2: 361-363

[24] Kavitha, G., Kavitha, R., "Dipping interference to supplement throughput in MANET", 2016, Journal of Chemical and Pharmaceutical Sciences, Vol-9, Issue-2: 357-360

[25] Michael, G., Chandrasekar, A.,'Leader election based malicious detection and response system in MANET using mechanism design approach", Journal of Chemical and Pharmaceutical Sciences(JCPS) Volume 9 Issue 2, April - June 2016.
[26] Michael, G., Chandrasekar, A.,'Modeling of detection of camouflaging worm using epidemic dynamic model and power spectral density", Journal of Chemical and Pharmaceutical Sciences(JCPS) Volume 9 Issue 2, April - June 2016.

[27] Pothumani, S., Sriram, M., Sridhar, J., Arul Selvan, G., Secure mobile agents communication on intranet,Journal of Chemical and Pharmaceutical Sciences, volume 9, Issue 3, Pg No S32-S35, 2016

[28] Pothumani, S., Sriram, M., Sridhar , Various schemes for database encryption-a survey, Journal of Chemical and Pharmaceutical Sciences, volume 9, Issue 3, Pg NoS103-S106, 2016

[29] Pothumani, S., Sriram, M., Sridhar, A novel economic framework for cloud and grid computing, Journal of Chemical and Pharmaceutical Sciences, volume 9, Issue 3, Pg No S29-S31, 2016

[30] Priya, N., Sridhar, J., Sriram, M. "Ecommerce Transaction Security Challenges and Prevention Methods- New Approach” 2016 ,Journal of Chemical and Pharmaceutical Sciences, JCPS Volume 9 Issue 3.page no:S66-S68 .

[31] Priya, N.,Sridhar,J.,Sriram, M."Vehicular cloud computing security issues and solutions" Journal of Chemical and Pharmaceutical Sciences(JCPS) Volume 9 Issue 2, April - June 2016

[32] Priya, N., Sridhar, J., Sriram, M. "Mobile large data storage security in cloud computing environment-a new approach" JCPS Volume 9 Issue 2. April - June 2016

[33] Anuradha.C, Khanna.V, "Improving network performance and security in WSN using decentralized hypothesis testing "Journal of Chemical and Pharmaceutical Sciences(JCPS) Volume 9 Issue 2, April - June 2016.

[34] Anuradha.C, Khanna.V, "A novel gsm based control for e-devices" Journal of Chemical and Pharmaceutical Sciences(JCPS) Volume 9 Issue 2, April - June 2016

[35] Anuradha.C, Khanna.V, "Secured privacy preserving sharing and data integration in mobile web environments " Journal of Chemical and Pharmaceutical Sciences(JCPS) Volume 9 Issue 2, April - June 2016.

[36] Sundarraj, B., Kaliyamurthie, K.P. Social network analysis for decisive the ultimate classification from the ensemble to boost accuracy rates 2016 International Journal of Pharmacy and Technology

[37] Sundarraj, B., Kaliyamurthie, K.P. A content-based spam filtering approach victimisation artificial neural networks 2016 International Journal of Pharmacy and Technology83.

[38] Sundarraj, B., Kaliyamurthie, K.P. Remote sensing imaging for satellite image segmentation 2016 International Journal of Pharmacy and Technology8 3.

[39] Sivaraman, K., Senthil, M. Intuitive driver proxy control using artificia intelligence 2016 International Journal of Pharmacy and Technology84.

[40] Sivaraman, K., Kaliyamurthie, K.P. Cloud computing in mobile technology 2016 Journal of Chemical and Pharmaceutical Sciences92.

[41] Sivaraman, K., Khanna, V. Implementation of an extension for browser to detect vulnerable elements on web pages and avoid click jacking 2016 Journal of Chemical and Pharmaceutical Sciences92.

\section{AUTHORS PROFILE}

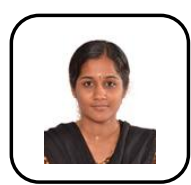

S.R.Srividhya Assistant Professor, Department of Computer Science \& Engineering, Bharath Institute of Higher Education and Research, Chennai, India

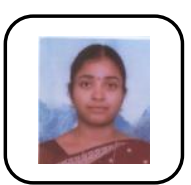

S.Pothumani, Assistant Professor, Department of Computer Science \& Engineering, Bharath Institute of Higher Education and Research, Chennai, India

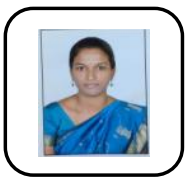

D.Jeya Priya, Assistant Professor, Department of Computer Science \& Engineering, Bharath Institute of Higher Education and Research, Chennai, India

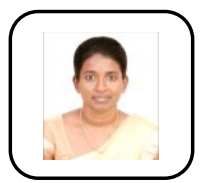

S.Theiva Sigamani, Assistant Professor, Department of Computer Science \& Engineering, Bharath Institute of Higher Education and Research, Chennai, India 